\title{
Evaluating the implementation of a chronic obstructive pulmonary disease management program using the Consolidated Framework for Implementation Research: a case study
}

\author{
Stefan Paciocco ${ }^{1}$, Anita Kothari ${ }^{2}$, Christopher J. Licskai ${ }^{3}$, Madonna Ferrone ${ }^{4}$ and Shannon L. Sibbald $5^{*}$
}

\begin{abstract}
Background: Chronic obstructive pulmonary disease (COPD) is a prevalent chronic disease that requires comprehensive approaches to manage; it accounts for a significant portion of Canada's annual healthcare spending. Interprofessional teams are effective at providing chronic disease management that meets the needs of patients. As part of an ongoing initiative, a COPD management program, the Best Care COPD program was implemented in a primary care setting. The objectives of this research were to determine site-specific factors facilitating or impeding the implementation of a COPD program in a new setting, while evaluating the implementation strategy used.

Methods: A qualitative case study was conducted using interviews, focus groups, document analysis, and site visits. Data were deductively analyzed using the Consolidated Framework for Implementation Research (CFIR) to assess the impact of each of its constructs on Best Care COPD program implementation at this site.

Results: Eleven CFIR constructs were determined to meaningfully affect implementation. Five were identified as the most influential in the implementation process. Cosmopolitanism (partnerships with other organizations), networks and communication (amongst program providers), engaging (key individuals to participate in program implementation), design quality and packaging (of the program), and reflecting and evaluating (throughout the implementation process). A peer-to-peer implementation strategy included training of registered respiratory therapists (RRT) as certified respiratory educators and the establishment of a communication network among RRTs to discuss experiences, collectively solve problems, and connect with the program lead.
\end{abstract}

\footnotetext{
* Correspondence: ssibbald@uwo.ca

${ }^{5}$ School of Health Studies, Faculty of Health Sciences, Department of Family Medicine, Schulich School of Medicine and Dentistry, The Schulich

Interfaculty Program in Public Health, Schulich School of Medicine and Dentistry, Western University, London, Canada

Full list of author information is available at the end of the article
}

(c) The Author(s). 2021 Open Access This article is licensed under a Creative Commons Attribution 4.0 International License, which permits use, sharing, adaptation, distribution and reproduction in any medium or format, as long as you give appropriate credit to the original author(s) and the source, provide a link to the Creative Commons licence, and indicate if changes were made. The images or other third party material in this article are included in the article's Creative Commons licence, unless indicated otherwise in a credit line to the material. If material is not included in the article's Creative Commons licence and your intended use is not permitted by statutory regulation or exceeds the permitted use, you will need to obtain permission directly from the copyright holder. To view a copy of this licence, visit http://creativecommons.org/licenses/by/4.0/. The Creative Commons Public Domain Dedication waiver (http://creativecommons.org/publicdomain/zero/1.0/) applies to the data made available in this article, unless otherwise stated in a credit line to the data. 
Conclusions: This study provides a practical example of the various factors that facilitated the implementation of the Best Care COPD program. It also demonstrates the potential of using a peer-to-peer implementation strategy. Focusing on these factors will be useful for informing the continued spread and success of the Best Care COPD program and future implementation of other chronic care programs.

Keywords: Chronic obstructive pulmonary disease, Implementation science, Implementation evaluation, Consolidated framework for Implementation research, Case study, Chronic disease management, Primary healthcare, Interprofessional teams

\section{Background}

The prevalence of chronic diseases in Canada has increased dramatically within the last few decades $[1,2]$. The number of individuals with chronic obstructive pulmonary disease (COPD) has almost doubled since 20002001 [3]. COPD is a debilitating chronic respiratory disease that accounts for the greatest number of chronic illness-related hospital admissions in Canada [4].

The use of team-based primary care has been explored to manage and combat the rise of chronic illnesses [5]. Chronic disease management programs using teambased primary care have been successful at mitigating the negative impacts of chronic diseases such as diabetes [6], chronic kidney disease [7], and congestive heart failure [8]. Using primary care to manage chronic diseases has become a successful part of comprehensive care, resulting in these models becoming a standard for chronic disease management and care around the world [9]. Unfortunately, there is limited literature describing how best to engage primary care in the management of COPD utilizing an integrated disease management approach. Indeed, in Canada and other jurisdictions the management of COPD falls below guideline standards, is reactive, not proactive, and in this way distinct from other conditions such as diabetes, where the obverse is true [10-14].

Canada has a universal health care system delivered under provincial jurisdiction. Ontario, Canada's most populous province (14.7 million), implemented family health teams (FHTs) as a collaborative primary care model consisting of providers from multiple disciplines including primary care clinicians and allied health professionals [15]. Since their implementation in 2005, FHTs have resulted in improved health outcomes and increased access to interprofessional care for patients in Ontario [16]. For patients with COPD who may struggle to navigate the health system, interprofessional teambased primary care is often a better alternative to emergency department or solo practitioner care [17].

Accessibility limits the impact of FHTs in general, and on patients with COPD specifically, as only approximately $20 \%$ of the population in Ontario has access to team care within an FHT $[15,18]$. The Best Care COPD program (BCC), the subject of this case study, is an efficacious interprofessional team care program that was developed within the FHT context [10]. The impact of BCC and other chronic disease management programs in primary care is dependent on effective implementation.

In order to effectively implement chronic disease management programs context-specific guidance is needed [19]. The implementation of any program into a new setting requires a rich understanding of local context, analysis of stakeholders, and evaluation of provider, organization, and system factors [1].

Using an evidence-based implementation framework for evaluation ensures research is theoretically grounded [20]. There are a number of available frameworks such as promoting action on research implementation in health services [21], the theoretical domains framework [22], and the consolidated framework for implementation research (CFIR) [23]. CFIR, an amalgamation of 19 different theories [23] considers constructs known to affect implementation (see Table 1 and Additional file 1) [24]. Information from CFIR can be used both prescriptively to facilitate the implementation of a program into specific local contexts or retroactively to evaluate implementation efforts [25]. We chose CFIR to evaluate the implementation of the BCC program.

In Ontario, a team-based COPD management program $(\mathrm{BCC})$ based in primary care focusing on patient selfmanagement through education, skills training and case management, was spread from the region where it was originally developed and implemented, to a neighbouring region using a peer-to-peer implementation approach. While current literature lacks a clear definition, or common name for peer-to-peer approaches in implementation, in general terms, peer-to-peer approaches involve using peer-led education and peer assessment as a method to support learning about the intervention [26-28]. Using a peer-to-peer approach implementation processes can facilitate buy-in and successful uptake/ program implementation [27]. Although more research is needed, preliminary evidence shows peer-to-peer learning as facilitating improved clinical education [29, 30]. The purpose of this research was to explore the 
Table 1 CFIR Categories and Definitions [24]

\begin{tabular}{ll}
\hline CFIR Category & Definition \\
\hline $\begin{array}{l}\text { Intervention } \\
\text { Characteristics }\end{array}$ & $\begin{array}{l}\text { The features of an intervention that might influence implementation. Eight constructs are included in intervention } \\
\text { characteristics. } \\
\text { Outer Setting }\end{array}$ \\
$\begin{array}{l}\text { The features of the external context or environment that might influence implementation. Four constructs are included in } \\
\text { outer setting. } \\
\text { Inner Setting }\end{array}$ & $\begin{array}{l}\text { The features of the implementing organization that might influence implementation. Twelve constructs are included in } \\
\text { inner setting. }\end{array}$ \\
Characteristics of & $\begin{array}{l}\text { Characteristics of individuals who are involved in implementation that might influence the implementation. Five constructs } \\
\text { Individuals }\end{array}$ \\
Process & Strategies or tactics that might influence implementation. Eight constructs are related to implementation process. \\
\hline
\end{tabular}

implementation of the $\mathrm{BCC}$ management program at a new clinical site in a different region, using the CFIR framework. Two research objectives guided this study.

1) Determine the enabling and impeding factors to implementation and spread of an interprofessional team-based primary care model, and

2) Explore the peer-to-peer approach to implementing a team-based primary care model.

Current literature lacks context empirical examples of the implementation of team-based primary chronic care models specifically for patients with COPD [31] as well as examples of using a peer-to-peer approach for implementation. Our research set out to fill this gap.

\section{Case description}

The BCC management program is a model of care consisting of primary care practitioners (physicians and nurse practitioners), nurses, a respirologist, RRT's with certified respiratory educator training, and health administrators all working together to provide COPDspecific care to patients. This model was created for the purposes of "delivering standardized, high-impact best-practices, within an interdisciplinary care model" ([32] p.6). BCC has demonstrated improved patient outcomes (such as reduced severe exacerbations) and reduced urgent health services use (including emergency department visits) [10]. Best practices in the program include creating action plans, skills training (including inhaler and breathing techniques), how to handle exacerbations, spirometry pre- and postintervention to measure progress, and medication and exercise prescriptions [33]. Program standardization and evaluation was supported by a program specific technology solution that guided every encounter and captured performance and outcome metrics [32]. In Canada, health care providers can obtain a certification as certified respiratory educator (a CRE program recognized by the Canadian Network of Respiratory
Care)[34]; in this case, all RRTs providing care within $\mathrm{BCC}$ had (or obtained) a certified respiratory educator designation.

An important component of the $\mathrm{BCC}$ program is an advisory committee, called the Primacy Care Innovation Collaborative (PCIC). The PCIC focuses on healthcare system innovation within primary care including participating in the development of provincial standards [35], and work to better integrate services within primary care through a 'medical home' approach [36]. Specific to BCC, PCIC supported and facilitated the robust evaluation and spread of the program outside the original region [32]. As a proof of concept project to demonstrate the programs ability to spread as well as to support the feasibility of the peer-led implementation approach, BCC was spread into a five-site FHT within Ontario (B-FHT). The unit of analysis in this case was considered the FHT. All individuals and organizations external to this were considered the outer setting.

Peer-to-peer implementation of this program was multi-pronged and began with BCC program leads presenting to healthcare teams and practitioners promoting the program. In this case, after the presentation to BFHT, the BCC RRT program lead worked directly with the RRT at B-FHT to commence program implementation. This began with training providers (RRTs) through both an internal three-day intensive didactic training $\mathrm{BCC}$ training process along with the external CRE training requirement. Peer-training continues as patients are recruited and enrolled into the $\mathrm{BCC}$ program and new RRTs shadow existing RRTs (and vice versa as new RRTs take on new patients). Peer implementation is also happening concurrently for executive directors - who can reach out to current executive directors already running the BCC program as well as for physicians, who can call on BCC physicians and/or the specialist physician (respirologist) for support. Research is currently on-going exploring the peer-to-peer implementation process in greater detail. 


\section{Methods}

Qualitative case study methodology was selected because it allows an in-depth exploration of a single selected entity or case [37]. Stake's constructivist case study was chosen specifically because he advocates for the researcher's active involvement in the case [38]. CFIR was used as a theoretical background to collect and analyze the data. CFIR has been used extensively in implementation and evaluation to become aware of influential factors, facilitate analysis, and organize the findings of an implementation [39].

\section{Setting and participants}

The BCC management program evaluated in this study was implemented within one FHT with five clinical sites in Southwestern Ontario. The FHT included different types of providers (physician, nurses, RRTs) and FHT staff working collaboratively to deliver healthcare and management education to patients. Implementation was evaluated at all sites as a single case, since providers interviewed worked across all five sites.

A convenience sample was used for recruitment with all having specific roles on the FHT. Participants included providers implementing BCC within the FHT (i.e., RRTs), providers referring patients to the BCC management program (primary care providers), and patients enrolled in the program (Table 2). Access to participants was granted through the FHT's executive director. We relied on providers to assist in patient recruitment; recruitment remained ongoing throughout the course of data collection and analysis.

Table 2 Participant Characteristics

\begin{tabular}{ll}
\hline Participant Type & Number of Participants \\
\hline Informed Consented Participants & 28 \\
Providers $(\boldsymbol{n}=\mathbf{2 4})$ & 1 \\
Executive Director & 2 \\
RRT/Certified Respiratory Educators & 1 \\
Clinical Lead/Nurse Practitioner & 1 \\
Physician & 2 \\
Nurse Practitioner & 3 \\
Reception & 1 \\
Registered Nurse Practitioner & 1 \\
Dietitian & 4 \\
Registered Nurse & 2 \\
Administration & 4 \\
Social Worker & 1 \\
Kinesiologist & 1 \\
Mental Health Counsellor & \\
Patients ( $\boldsymbol{n}=\mathbf{4}$ ) &
\end{tabular}

\section{Data collection}

Data were collected from a variety of qualitative sources which collectively contributed to the analysis to ensure that the individual, collective, and documented experiences of participants were obtained. Focus groups were conducted to gather the collective experience of the participants [40]. Provider and patient focus groups were conducted independently during sites visits. Observational field notes were taken during the site visits. The purpose of the site visits and field notes were to allow for substantiation of the data through triangulation, as well as to provide an element of reflexivity [38]. Data collection tools were guided by CFIR [24]; interview and focus group questions were built from CFIR as well as from expert opinion (i.e., those involved in the program delivery and implementation). Questions were considered and subsequently selected by the research team with the main goal of eliciting important information about implementation. All questions were piloted and used in previous research [41]. Final focus group and interview guides are available upon request.

One-on-one phone interviews with additional primary care providers who referred patients to the BCC program were conducted. The goal was to gather additional views about the implementation of the program from individuals working indirectly with the program.

Review of FHT documents such as memorandums of understanding, reports, and data sharing agreements produced contextual data that was primarily used to support analysis. Documents were accessed through the executive director of the site and the PCIC.

Throughout the entire research process, written reflexive notes were created by the researchers to ensure that the interviewer's thoughts and assumptions could be incorporated during data analysis and interpretation [38].

\section{Data analysis}

To ensure a thorough understanding of the context of the site and data collected, an ongoing deductive coding strategy based on CFIR was used, supported by NVivo. Data were coded by 3 researchers (SP, SLS, SM) into related CFIR constructs and sub-constructs. To acknowledge and account for data that did not directly fit into CFIR more effectively (such as patient experience), inductive coding was also performed. Discrepancies were discussed and if there were multiple agreeable codes, segments of data were double-coded. Data categorization methods were performed as per Stake [38]'s recommendations: direct interpretation and categorical aggregation. All analysis was discussed by the entire research team including a primary care physician. The key enabling constructs were identified as most important during the data analysis process due to being discussed most frequently by the participants and were determined to 
have a greater impact on implementation through member checking and research team discussion.

While implementation at the FHT took place over 5 sites, the implementation was viewed and evaluated as a single case. Implementation success was qualitatively assessed, using data collected from the provider and patient participants. Throughout data collection, participants reported a high level of satisfaction with the program implementation and delivery.

Field notes and collected documents were integrated into our analysis iteratively. This was done by deductively coding information related to implementation in a similar manner as described above. This additional data was then used in conjunction with focus group and interview data to identify facilitators and barriers to implementation. Participants received an interim report which was discussed during a focus group. Feedback was incorporated into our results. A member check (method of qualitative data triangulation) was conducted to explore the validity of our findings. Member checking involved returning to the implementation site after initial data collection and analysis for a follow-up visit. This allowed the researchers to confirm their interpretation of the data with the participants as well as ask additional questions.

\section{Results}

In total, three focus groups ( 2 provider, 1 patient), $n=1$ phone interview, and $n=1$ key informant interview were conducted involving a total of 28 participants. $n=24$ providers and $n=4$ patients (Table 3). All FHT providers invited to participate took part in the study. Informed consent was obtained from all participants prior to any data collection. Response rate for the patients was unknown due to the recruitment of patients being performed by RRTs.

\section{Factors affecting Implementation}

Our results are presented according to the 5 main categories of CFIR, while incorporating results from the patient perspective and peer-to-peer implementation. Quotes are provided to illustrate our findings.

\section{Intervention characteristics}

Design quality and packaging The design quality and packaging of the program was discussed as a critical factor in the decision to adapt the model and its successful implementation. This included the presence of highly trained team members with experience implementing and delivering the $\mathrm{BCC}$ program as part of the peer-topeer approach. They acted in a hands-on and advisory capacity during and following implementation. They trained individuals on how to execute the program as well as offered continued advice post-implementation.

When [the BCC Program Leads] came in, they knew what the expectations were, they knew what the outcomes would look like. They had that experience, where we were just fishing and hoping we would get the outcomes we were hoping for, but we didn't really have the experience with that to confidently approach all those physician groups (Provider \#3, Provider Focus Group \#1).

Complexity Participants believed previous program success translated to a smooth process for B-FHT staff in terms of program implementation. "Right away we were sold ... it's an easy sell because they... drop a program and a person attached to it in your lap. It is zero work" (Provider \#2, Key Informant Interview \#1). The participants further discussed the low complexity of the implementation. "Once... the patients were being seen, there's not a lot of other admin, oversight really required. It's the simplest honestly. So simple... everything just fell into place." (Provider \#2, Provider Focus Group \#1). Providers elaborated on how they felt the implementation was done effectively and efficiently. "It seems really simple ... it didn't really disrupt ... your everyday (Provider \#1). If we could roll out every single program that way, it'd be great" (Provider \#2, Provider Focus Group \#1).

Providers felt the recruiting of patients into the program was smooth and effective. Patients concurred with this statement, saying: "[I] flowed right through [into the new program]" (Patient Focus Group \#1). Even though

Table 3 Type of Data Collection

\begin{tabular}{|c|c|c|}
\hline Type of Data Collection & Number of Sessions & Number of Participants \\
\hline Provider Focus Groups & 2 & 23 \\
\hline Patient Focus Groups & 1 & 4 \\
\hline Field Notes & 3 & 6 \\
\hline Physician Interview & 1 & 1 \\
\hline Documents & $\mathrm{n} / \mathrm{a}$ & 4 \\
\hline Key Informant Interview ${ }^{a}$ & 1 & 1 \\
\hline
\end{tabular}

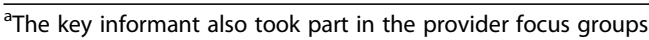


patient awareness of the transition into the program was low; providers believed this facilitated implementation because it did not disrupt usual patient appointments. Providers appreciated being able to spend more time focusing on patient transition and less on other aspects of implementation.

Relative advantage Providers discussed that prior to implementation of the BCC program, B-FHT had been unsuccessful in their attempts to create their own COPD management program. The relative advantage of the BCC program offered a successful and adaptable solution for their patients.

There [were] challenges. One, that there wasn't an established program, for [the RRT] to mimic. And two ... we are a multi-site organization, and with a 0.5 [full-time equivalent RRT] position it is really hard to establish any programming without a consistence presence. Which ... just wasn't possible (Provider \#2, Key Informant Interview \#1).

Physician \#1 echoed this explaining the advantage of having a comprehensive COPD specific care program in "free (ing) me up to focus on other things during appointments" (Phone Interview \#1). Providers agreed this was a clear benefit of the program. The physician was confident in the abilities of the newly educated RRTs to provide COPD-specific care to the patients. As a result, they were able to focus their time on a patient's other concerns and needs, allowing for more efficient use of time during appointments.

Patients also appreciated the coordinate afforded by the BCC program explaining how they prefer this program to alternatives they have previously experienced. "I've got a specialist that I'm not agreeing with and that's not helping me, I might as well not even go to him. [The RRT in this program] is doing [more for me] than he is" (Patient \#4, Patient Focus Group \#1). From the patient's view, the RRT was delivering better care for their COPD than was the specialist working external to the program.

Providers discussed the challenges of adding the program's new reporting technology on top of existing technology. "They have their own system ... I hate adding systems. That was the one thing probably that I really was not happy about ... we have an [electronic medical record] (EMR). We're seeing our patients but will be documenting in [the BCC's system]" (Provider \#2, Key Informant Interview \#1).

\section{Outer setting}

Patient needs and resources Providers discussed the patient needs in the community as one of the reasons B-
FHT proceeded with program implementation. "COPD was a problem. And COPD patients are complex, timeconsuming, and costly. There's plenty of patients and ongoing work to keep you busy full-time" (Provider \#3, Provider Focus Group \#1).

Cosmopolitanism Participants described B-FHT's cosmopolitanism efforts (i.e., efforts to collaboration with external organizations) to be instrumental in implementing the program. There was a shared agreement amongst providers about how "[the BCC's] guidance was key for us being successful so quickly" (Provider \#3, Provider Focus Group \#1). In addition to working with the BCC program team, the B-FHT had the chance to learn from the PCIC and strengthen their coordinated efforts with the local hospital.

We actually built it to [be] part of one [program] to refer hospital discharges... with the COPD diagnosis... to automatically send a message to the RRT saying that, that person was discharged (Provider \#5, Provider Focus Group \#2).

B-FHT had a pre-existing relationship with the local hospital, which had been responsible for performing diagnostic lung function testing (spirometry). The collaboration was challenged because the BCC program standard was for the RRT to complete the spirometry in the local B-FHT office. Transferring spirometry from the hospital to the B-FHT office was a concern because it meant shifting care away from the hospital. A compromise was reached allowing B-FHT to maintain the relationship with the hospital and respecting the requisite program fidelity.

\section{Inner setting}

Networks and communication In implementing BCC, a network of RRTs was created to enhance communication and facilitate a peer-to-peer approach. This was discussed as a key factor for implementation success because it facilitated information sharing across a broad context which informed practice. This peer-to-peer approach facilitated the training of providers within B-FHT and supported implementation of the program. "The RRTs have their own network where they communicate with each other" (Provider \#6, Provider Focus Group \#2). "It's an opportunity for them to ... say what's working, what's not working, what are they finding out there in the field. They [also] have a [messaging] group" (Provider \#4, Provider Focus Group \#2). The peer-to-peer approach strengthened communication between providers within the program. BCC Program leads were seen as a highly valued resource for providers. "[She is] 
always available if we run into any problems or have questions ... [we] just reach out to her directly" (Provider \#4, Provider Focus Group \#2).

Occasionally, poor communication amongst leadership and providers acted as a barrier to implementation. One provider noted "if [meetings are announced] last minute or we forget... it's just not going to be priority to move all our other appointments around ... (Provider \#7, Provider Focus Group \#2). This was especially significant when the meetings included training or were meant to connect new providers.

Readiness for Implementation - available resources Resource support was also discussed as a factor for successful implementation. Typically, RRTs were newly hired to support program delivery, however "[B-FHT] (used) their existing [RRT] to deliver [the BCC] model" (Provider \#4, Provider Focus Group \#2). This was both seen as a facilitator (i.e., using available resources) and as a barrier (i.e., requiring unlearning of existing, possibly hindering practices and habits). With the BCC program, the current RRT role was expanded into a fulltime position, making it easier to implement the program in B-FHT's multi-site clinical setting.

Administrative support including affirmation from senior management, secretarial/scheduling support, and chart audit support from the BCC leads was particularly important during the initial stages of implementation. Without this support, RRTs believed they would have had to spend excessive time doing administrative work rather than focusing on patient care. "If you're rolling a program like this into a [FHT] office without a lot of allied health, those cold calls ... for [a patient's] first visit might be time-consuming if they didn't have that support" (Provider \#3, Provider Focus Group \#1).

However, the providers discussed how data in the primary care EMR, distinct from the program electronic health record, was of poor quality. This hampered the ability for the program RRT to identify high risk individuals. Providers felt "better data in [the EMR] would've helped. But that's not... likely or possible" (Provider \#2, Provider Focus Group \#1).

\section{Characteristics of individuals}

Self-efficacy Peer-to-peer implementation allowed providers to learn about the program and its intended implementation first-hand from experienced RRTs. Providers felt this increased their confidence in program delivery. "I really appreciate having people who are experts in COPD care that can give me recommendations. The more knowledge I start to feel comfortable with ... in COPD in particular is because of [the RRT]" (Provider \#3, Provider Focus Group \#1).
Throughout focus group discussion, patients remarked how "you follow what [the RRT] says and [what] the doctor says and ... my quality of life is better" (Patient \#2, Patient Focus Group \#1). This trust built between the providers and patients was important for implementation success. Patients reported they felt empowered to manage their care and talked about sharing that with peers and family members.

Knowledge and beliefs about the intervention Providers and patients valued the program from the start. This buy-in of the program enhanced implementation. Providers and patients highly valued the RRT role and expressed many positive views about the RRTs: "If we could clone [the B-FHT RRT], that's part of what has ... made it so successful for us is that she was able to just come in" (Provider \#2, Provider Focus Group \#1).

\section{Process}

Engaging Support from senior leadership was essential during the implementation process. The initial impetus to implement the program stemmed from collaboration between RRTs, however, the executive director of the site fully supported and actively facilitated implementation. Participants reported buy-in from senior leadership as a major facilitator to implementation. In addition, other primary care providers engaged with the program throughout the implementation process by learning about program offerings and supporting patient recruitment into the program.

Initially... we were reminded to refer any of our COPD patients for the [RRTs] to make sure that there was a demand. I would really emphasize the importance of frequent reminders to ... everyone who would refer patients to the program, reminding them of what kinds of [patients] they can and should refer (Physician \#1, Phone Interview \#1).

Providers praised the BCC's intensive approach to early implementation. They explained how it resulted in buyin from the start.

That initial, really strong blitz on talking to, providing the education to the physicians, speaking with the physician groups individually, getting the searches ready to go... It seemed like that period was probably short, but intense, and necessary (Provider \#3, Provider Focus Group \#1).

Providers also reported the peer-to-peer approach enabled rapid implementation the program. Peer-to-peer training was conducted by an RRT and supported by a 
respirologist. Provider \#1 said that she "sat with somebody who'd been doing it for twenty, five, and three years" respectively (Provider Focus Group \#1). Provider \#2 elaborated: "the training piece was also big ... that training then does ensure that there's a consistency in [program delivery]" (Provider Focus Group \#1).

Reflecting and evaluating In an effort to collect data on the implementation and performance of the BCC management program, feedback data was collected by BFHT and the PCIC. Data was collected using patient satisfaction surveys as well as regular debriefing with stakeholders. This data was then used to facilitate adjustments to the implementation and execution of the program as needed.

When discussing the results of this data during reflection of the implementation process, many participants boasted at its success. "I don't have a single criticism about the program. I really can't think of how it could have been done better" (Provider \#2, Key Informant Interview \#1). "We always look at outcome measures, which are always really positive." (Provider \#3, Provider Focus Group \#1). Providers explained that not only is patient satisfaction increasing but "hospital admissions had been decreased" (Provider \#1, Provider Focus Group \#1). When asked to provide advice to other teams considering implementing the program, a key informant said:

Take advantage of this program it is zero work on your end. They will come in and do everything and they will also return. If you are struggling at any point... having trouble identifying patients or... with physician buy-in, if you're having process issues, they are happy to return... my only advice actually, is "say yes" (Provider \#2, Key Informant Interview $\# 1)$.

Patients echoed provider's positive views of the program and focused their conversation on the care they received from the program. Patients reflected on their own care and found value in their improved overall quality of life: "[The RRT] was very thorough ... with their explanations of your puffers [and] your medication ... [the RRT] gave you [advice]... I find it very good, helpful (Patient Focus Group \#1).

\section{Discussion}

This implementation case study was the pilot site to evaluate the opportunity for program spread to multiple sites across multiple regions. All of the CFIR constructs analyzed affected implementation, however five were determined as key enabling constructs (based on the frequency of their occurrence in participant comments and in documents) to consider when implementing a teambased chronic care program such as the BCC program: cosmopolitanism, networks and communication, engaging, design quality and packaging, and reflecting and evaluating.

CFIR constructs acting as barriers to be managed during implementation were also identified. These were: complexity (of the new patient reporting system); communication (between providers and management as well as between providers and specialists); and lack available resources (in this case, lack of quality data in the clinicbased primary care EMR).

In a systematic review, Kadu and Stolee [25] evaluated the implementation of chronic care management models in primary care settings. To do this, they used CFIR constructs to determine facilitators and barriers to implementation. Although within each of the 22 studies included there were many combinations of all 39 CFIR constructs affecting implementation, they identified seven constructs which had a meaningful effect on implementation across the studies included in their review. These were: networks and communication, culture, implementation climate, structural characteristics, engaging, executing, readiness for implementation, and knowledge and beliefs about the intervention [25]. Our analysis approach overlapped the Kadu and Stolee [25] review in three constructs: networks and communication, engaging, and knowledge and beliefs about the intervention. This is not to say the others were not important during the implementation of the BCC program, they simply did not appear frequently in our analysis. Our study shows, as others do, that it is a combination of multiple CFIR constructs which meaningfully affect successful implementation [24]. Although Kadu and Stolee [25] evaluated the implementation of chronic care management models in primary care settings, there were no studies among the 22 included that focused specifically on COPD. This may be one reason why only 3 of Kadu and Stolee [25]'s primary constructs aligned with our finding. Our study adds to this work by providing insight into the implementation of a COPD-specific management program.

\section{Key enabling CFIR constructs Cosmopolitanism}

The strong cosmopolitan relationship developed between B-FHT and the BCC leadership was supported by the evidence-based characteristic of the program. Participants could easily align cognitively and philosophically on evidence-based treatment standards. It also facilitated networking with external organizations. When implementing a chronic care management program, it is important to first consider collaboration with external organizations [1]. The established networks present with 
PCIC and other RRT networks gave B-FHT providers opportunities to collaborate and gain access to knowledge from a broad network of providers.

Literature on the implementation of chronic care models states that when a collaborative effort is made with external organizations, implementation and sustainability efforts are more effective [1] and factors such as communication, cohesion, and role primacy increase [42]. This finding is mimicked in recent works by Brown et al. [43] and Huang et al. [44]. In our case study, BFHT's partnership with the BCC program team acted as a key facilitator to implementation.

\section{Networks and communication}

Networks and communication or information and communication as termed in Davy et al. [1] are facilitators within literature that were important in this case study. The BCC program in its initial stages created strong networks and communication which supported program delivery [45]. Enhancing communication among providers and establishing provider-specific networks are key components to facilitating the peer-to-peer implementation [46]. Kadu and Stolee [25] uphold that strong implementation efforts require established internal communication networks. This helps improve long-term sustainability, keep track of patients, and proactively notice gaps in service provision [1]. When information and communication systems are not in place or are insufficient, they can become a significant barrier to implementation [47].

\section{Engaging}

Engaging champions in implementation efforts is a key factor to success [48]. Champions can help increase provider support through enthusiasm and support [48]. Participants identified champions within the PCIC, B-FHT management, and the RRT as peer leaders during implementation. When leadership is engaged, there is more likely to be support from other providers $[1,25]$. Alternatively, if leadership is not engaged, stakeholders may begin to lose interest [48].

\section{Design quality and packaging}

The excellent design and packaging of the intervention positively influenced B-FHT's decision to implement and supported the ease of implementation. The BCC structured program coupled with the support from BCC program team, the PCIC and other RRT networks infused quality within the whole implementation. Literature has shown that poor design quality or lack of attention to packaging can be a barrier to implementation [47-49]. Well-designed educational materials, such as those used by BCC, can also facilitating implementation by fostering engagement and increasing clarity [50].

\section{Reflecting and evaluating}

In our study, evidence-based data, specifically regular reflecting on performance metrics and peer-to-peer feedback methods were used effectively to support implementation. Integrating regular monitoring and evaluation throughout program delivery can support implementation efforts [10]. Regular debriefing with stakeholders to allow for critical reflection and evaluation is also important and should be embedded early on in implementation $[1,38]$. Feedback systems that are used to support implementation can also work to support program sustainability $[1,49]$.

\section{Other CFIR factors affecting implementation}

There were other CFIR constructs found to be supportive of implementation, but not necessarily as impactful as those already discussed. Complexity: When stakeholders believe an implementation is simple, the program is more easily implemented into practice [51]; overly complex programs or processes can impede the implementation of chronic care models [1]. In our case, the simplicity of implementation, attributed to the high level of support from the BCC program team, was a facilitator - often supporting other key constructs such as engagement and reflection. Patient Needs and Resources: There is consensus in the literature around the importance of considering context in implementation efforts - this should consider factors at multiple levels including patient, provider, team, organization, and community $[1,24,51-53]$. A systematic review by Davy et al. [1] described how implementation is enabled when providers believe their intervention helps their patients, rather than a change for change's sake. The BCC program in our study addressed a clear and growing need for COPD-specific care in the B-FHT community. Relative Advantage: Providers believed the program had a relative advantage to what was currently being offered to patients; this, combined with the perceived need within their community, facilitated implementation. Our results echo the findings of Greenhalgh et al. and others [47, 51] who have explained the importance of programs having a "clear, unambiguous advantage in either effectiveness or cost-effectiveness [as] more easily adopted and implemented" [51 p.594]. Readiness for Implementation - Available Resources: There is consensus in the literature that a lack of resources, or a misuse of available resources (ex. time, funding, and space) can hinder implementation $[1,54,55]$. In our study, the addition of a full-time RRT position made a meaningful difference in the overall provision of services. While the addition of resources can support implementation, it is important to ensure any resource is added or appropriate for the context [1]. Self-Efficacy/Knowledge and Beliefs about the Intervention: Ensuring providers 
possess the necessary skills to achieve implementation goals is essential [1]. BCC's training helped build confidence and empowerment in providers, and the peer-topeer approach facilitated buy-in to the possibilities of the program (i.e., positive outcomes for patients and providers) [43]. Low self-efficacy and high staff turnover can undermine the implementation process $[56,57]$. When providers feel more confident in their scope of practice, they can build trust and support implementation.

\section{Peer-to-peer implementation}

Literature describes peer-led education as a powerful approach to achieving program goals and objectives [2628]. To our knowledge, using a peer-led approach to implementation has not been directly studied, however our case shows the potential for such an approach. In this case RRTs, as regulated health professionals with specialized COPD training as certified respiratory educators, worked directly with other RRTs in implementation and program delivery. Their professional-efficacy and commitment to program goals was amplified by regular peer-to-peer education and training. The providers mentioned how regular training sessions, along with the program lead's availability throughout implementation, as essential in the success of program implementation and ultimately the program overall. The creation of the RRT network, which allowed RRTs to share emerging ideas and concerns about the program and their patients throughout and following implementation, was seen as a key component successful implementation. Positive views surrounding the program and the critical role of the RRTs during implementation were shared by all participants echoing the findings of Pfadenhauer et al. [58] who explained how key individuals who can be champions during an implementation can enhance overall program success.

\section{Limitations}

Our small sample size and in depth look at one case meant there was a potential for both social desirability bias and the Dunning-Kreuger effect (the belief that implementation was better than it actually was) [59]. The latter point is mitigated by positive outcomes reported in the seminal randomized control trial from which the spread initiative was launched [10]. Participants all worked together which may have affected their willingness to share experiences; however, we ensured there were multiple opportunities for feedback, including our formal member checking. We acknowledge our results are specific to this case study, however our standardized methodology and evaluation framework support our results can being interpreted in other contexts. Triangulation of data and member checking supported the rigor and trustworthiness of our data. Due to the fact this is a single case study, determination of important factors affecting implementation success was based on in-depth discussion with our research team and research participants; we also relied on inference from factors including the frequency with which particular barriers/facilitators were mentioned. Future research is ongoing examining the variability in implementation success across multiple sites and examining differences in facilitators at successful sites versus barrier's unsuccessful sites. Even though the findings came from a single case study, our results will be useful in planning spread and implementation efforts of the BCC program at other sites and for others wanting to implement a chronic disease management program.

\section{Conclusion}

This study was conducted to understand the facilitators and barriers that affect the implementation of a chronic care management program for patients with COPD in a primary care context. Our aim was to determine enabling factors of implementation and spread of an interprofessional team-based primary care model to support future spread efforts. The five most influential constructs to implementation according to CFIR were cosmopolitanism, networks and communication, engaging, design quality and packaging, and reflecting and evaluating. Our results align with those from the literature including Kadu and Stolee [25]'s systematic review using CFIR of factors affecting the implementation of chronic disease management programs. The successful implementation of the BCC program within B-FHT can be attributed to multiple factors. The program's overall success was well regarded by both providers for its positive outcomes and by patients for the improvement in their COPD-specific care. Overall, CFIR was a suitable determinant framework for conducting our study. It provided a broad and useful set of constructs from which was able to determine factors affecting the implementation of the $\mathrm{BCC}$ management program. We also aimed to understand the peer-to-peer approach to implementation. This implementation was understood as vital to assist in communication, engagement, and self-efficacy of providers.

This study provides a practical example of the various factors that facilitate the implementation of the BCC management program. It also demonstrates the potential of using a peer-to-peer implementation strategy. Focusing on these factors will be useful for informing the continued spread and success of the BCC program and future implementation of other chronic care programs.

\section{Abbreviations}

COPD: Chronic Obstructive Pulmonary Disease; FHT: Family Health Team; CFIR: Consolidated Framework for Implementation Research; EMR: Electronic 
Medical Record; RRT: Registered Respiratory Therapist; BCC: Best Care COPD; $\mathrm{PCIC}$ : Primary Care Innovation Collaborative

\section{Supplementary Information}

The online version contains supplementary material available at https://doi. org/10.1186/s12913-021-06636-5.

Additional file 1. Consolidated Framework for Implementation Research Constructs. This document provides an organized list including the categories and constructs of the consolidated framework for

implementation research, as well as a short definition for each construct.

\section{Acknowledgements}

We would like to acknowledge the participants in this study. Thank you to Dr. Judy Belle Brown, Dr. Sayra Cristancho and the entire research team for your guidance throughout this process. Thank you especially to Dr. Shiraz Malik for your assistance during the data analysis process. Thank you also to Alvina Asif Jiwani who assisted with referencing for this manuscript.

\section{Authors' contributions}

SP was the graduate student during the research process. SP was lead interviewer during focus groups and interviews. SP performed all of the initial deductive and inductive coding and drafted the first version of the manuscript. AK was a member of the advisory committee and provided advice on the scope and direction of the research. AK reviewed the manuscript during writing, provided feedback and made edits throughout the entire process. SLS supported data collection and analysis. SLS created field notes during focus groups. SLS was involved in the deductive and inductive coding of the data. SLS contributed to the writing of the manuscript. CJL an MF made substantial contributions to the development of the BCC program as members of the $\mathrm{PCIC}$, supported data collection at BFHT sites, and in the interpretation of data for the work. CJL and MF reviewed the manuscript critically for important intellectual content. By design, CJL and MF did not participate in the direct acquisition, coding, or primary interpretation of the data. All authors read and approved the final manuscript.

\section{Authors' information}

Stefan Paciocco ${ }^{1}, \mathrm{MSC}$; Anita Kothari ${ }^{2}$, PhD; Christopher J. Licskai, MD³ Madonna Ferrone ${ }^{4}$; Shannon L. Sibbald ${ }^{2,3,5}$, PhD.

Health and Rehabilitation Sciences -Western University ${ }^{1}$, School of Health Studies, Faculty of Health Sciences - Western University ${ }^{2}$, Department of Family Medicine, Schulich School of Medicine and Dentistry ${ }^{3}$, Asthma Research Group Incorporated ${ }^{4}$, The Schulich Interfaculty Program in Public Health, Schulich School of Medicine and Dentistry ${ }^{5}$.

When doing constructivist research, we must have an active personal role in data collection and analysis. This will be done by stating preconceived notions and assumptions and discussing how they affected the interpretation of the data. SLS had worked alongside the PCIC in the past and knew their program and implementation strategy well. The initial iteration of the program was evaluated and deemed a notable success. As a result, SP possessed an understanding that the BCC management program was a successful program. Although SP found the majority of results to be positive, on occasion, he may have been more likely to code in a positive manner rather than neutral or negative. Therefore, there may exist other interpretations of which the researchers were not immediately aware of which may have been understood by another researcher unaware of the program's successful origins.

\section{Funding}

This study was funded through a 2-year grant from Lawson Research. Lawson Research had no role in the design of the study, data collection, data analysis, or preparation of the manuscript.

\section{Availability of data and materials}

The datasets generated and analyzed during the current study are not publicly available in order to maintain the confidentiality of the participants but are available from the corresponding author on reasonable request.

\section{Declarations}

\section{Ethics approval and consent to participate}

The Western University Ethics and Review Board granted ethics approval for this study (Project Number: 108415). Additionally, Lawson Research funded this project, and we were required to submit a Research Database Application (ReDA ID: 6416), which was also approved. As this research involved human participants and human data, all research was performed in accordance with the Declaration of Helsinki. Informed consent to participate was obtained from each participant including the executive director through the reading, explanation, and signing of a letter of information and informed consent for participation and publication.

\section{Consent for publication}

Informed consent for publication was included in the letter of information and informed consent forms signed by all participants including the executive director of B-FHT. The letter of information and informed consent form signed by participants were obtained for informed consent for both participation and publication. No information was published identifying an individual person, therefore not applicable.

\section{Competing interests}

The authors declare that they have no competing interests.

\section{Author details}

${ }^{1}$ Health and Rehabilitation Sciences, Western University, London, Canada. ${ }^{2}$ School of Health Studies, Faculty of Health Sciences, Western University, London, Canada. ${ }^{3}$ Department of Family Medicine, Schulich School of Medicine and Dentistry, Western University, London, Canada. ${ }^{4}$ RRT-CRE, Asthma Research Group Inc., London, Canada. ${ }^{5}$ School of Health Studies, Faculty of Health Sciences, Department of Family Medicine, Schulich School of Medicine and Dentistry, The Schulich Interfaculty Program in Public Health, Schulich School of Medicine and Dentistry, Western University, London, Canada.

Received: 17 March 2021 Accepted: 14 June 2021

Published online: 21 July 2021

\section{References}

1. Davy C, Bleasel J, Liu H, Tchan M, Ponniah S, Brown A. Factors influencing the implementation of chronic care models: A systematic literature review. BMC Family Pract. 2015;16(1). [cited 2019 Feb 05] Available from: https://doi. org/10.1186/s12875-015-0319-5 DOl: https://doi.org/10.1186/s12875-015-031 9-5.

2. Yeoh E, Wong MC, Wong EL, Yam C, Poon C, Chung RY, et al. Benefits and limitations of implementing chronic care model (CCM) in primary care programs: A systematic review. Int J Cardiol. 2018;258:279-88. [cited 2019 Feb 01] Available from: https://doi.org/10.1016/j.ijcard.2017.11.057.

3. Prevalence of chronic diseases among Canadian adults. Canada: Public Health Agency of Canada; 2019 Dec 9. 1 p.

4. Benady S. The human and economic burden of COPD: A leading cause of hospital admission in Canada. Ottawa: Canadian Thoracic Society; 2010.

5. Katon WJ, Lin EH, Von Korff M, Ciechanowski P, Ludman EJ, Young, B, et al. Collaborative care for patients with depression and chronic illnesses. N Engl J Med. 2010;363(27):2611-20. [cited 2019 Jan 19] Available from: https://doi. org/10.1056/nejmoa1003955.

6. Stellefson M, Dipnarine K, Stopka C. The chronic care model and diabetes management in US primary care settings: A systematic review. Prev Chronic Dis. 2013;10. [cited 2019 Mar 09] Available from: https://doi.org/10.5888/ pcd10.120180 DOl: https://doi.org/10.5888/pcd10.120180

7. Armstrong N, Herbert G, Brewster L. Contextual barriers to implementation in primary care: an ethnographic study of a programme to improve chronic kidney disease care. Fam. Pract. 2016;33(4):426-31. [cited 2019 Mar 09] Available from: https://www.ncbi.n/m.nih.gov/pmc/articles/PMC4957013/ DOl: https://doi.org/10.1093/fampra/ cmw049.

8. Bodenheimer T, Wagner EH, Grumbach K. Improving primary care for patients with chronic illness. JAMA. 2002;288(15):1909. [cited 2019 Apr 06] Available from: https://doi.org/10.1001/jama.288.15.1909 DOl: 10.1001/jama. 288.14. 1775. 
9. Garland-Baird L, Fraser K. Conceptualization of the chronic care model. Home Healthc Now. 2018 [cited 2019 Mar 09];36(6):379-85. Available from: https://doi.org/10.1097/nhh.0000000000000699.

10. Ferrone M, Masciantonio MG, Malus N, Stitt L, O'Callahan T, Roberts Z, et al. The impact of integrated disease management in high-risk COPD patients in primary care. NPJ Prim. Care Respir. Med.. 2019;29(1). [cited 2019 Jan 01] Available from: https://doi.org/10.1038/s41533-019-0119-9.

11. Kruis AL, Smidt N, Assendelft WJJ, Gussekloo J, Boland MRS, Mölken MR, et al. Integrated disease management interventions for patients with Chronic obstructive pulmonary disease. Cochrane Database Syst. Rev 2013; (10). [cited 2021 Feb 10] Available from: https://pubmed.ncbi.nlm.nih. gov/24108523/

12. GOLD Committee. Global Initiative for Chronic Obstructive Lung Disease: Global strategy for the diagnosis, measurement, and prevention of chronic obstructive pulmonary disease (2021 Report). Available from: https:// goldcopd.org/wp-content/uploads/2020/11/GOLD-REPORT-2021-v1.1-2 5 Nov20 WMV.pdf

13. Khan A, Dickens AP, Adab P, Jordan RE. Self-management behaviour and support among primary care COPD patients: cross-sectional analysis of data from the Birmingham Chronic Obstructive Pulmonary Disease Cohort. npj Prim. Care Respir. Med. 2017;27:46. [cited 2021 Mar 4] Available from: https://pubmed.ncbi.nIm.nih.gov/28729620/

14. Lundell S, Tistad M, Rehn B, Wiklund M, Holmner $\AA$, and Wadell K. Building COPD care on shaky ground: a mixed methods study from Swedish primary care professional perspective. BMC Health Serv Res. 2017;17, 467. [cited 2021 Mar 12] Available from: https://bmchealthservres.biomedcentral.com/a rticles/10.1186/s12913-017-2393-y\#citeas

15. Ministry of Health and Long-Term Care. Family Health Teams. Canada: Ministry of Health and Long-Term Care / Ministère de la Santé et des Soins de longue durée; 2016. Available from: http://www.health.gov.on.ca/en/pro/ programs/fht/

16. Nisbet G, Dunn S, Lincoln M, Shaw J. Development and initial validation of the interprofessional team learning profiling questionnaire. J Interprof Care. 2016;30(3):278-87. [cited 2020 Feb 14] Available from: https://doi.org/10.31 09/13561820.2016.1141188.

17. Rosser W, Colwill JM, Kasperski J, Wilson L. Progress of Ontario's family health team model: A patient-centered medical home. Ann. Fam. Med. 2011;9(2):165-71. [cited 2019 Jan 07] Available from: https://doi.org/10.13 70/afm.1228 DOl: https://doi.org/10.1370/afm.1228.

18. Statistics Canada. Population estimates on July $1^{\text {st }}$, by age and sex. Canada: Statistics Canada; 202103 15. Available from: https://www150.statcan.gc.ca/ t1/tbl1/en/tv.action?pid=1710000501\&pickMembers\%5B0\%5D=1. 7\&pickMembers\%5B1\%5D=2.1\&cubeTimeFrame.startYear $=201$ 6\&cubeTimeFrame.endYear $=2020 \&$ referencePeriods $=20160101 \% 2$ C20200101

19. Wensing M. Implementation science in healthcare: Introduction and perspective. Z Evid Fortbild Qual Gesundhwes. 2015 ;109(2):97-102. [cited 2019 Jan 05]Available from: https://doi.org/10.1016/j.zefq.2015.02.014 DOl: https://doi.org/10.1016/j.zefq.2015.02.014.

20. Nilsen, P. Making sense of implementation theories, models and frameworks. Imp Sci. 2015;10(1). [cited 2020 May 19] Available from: https:/doi.org/10.1186/ s13012-015-0242-0 DOl: https:/doi.org/10.1186/s13012-015-0242-0.

21. Kitson A, Harvey G, McCormack B. Enabling the implementation of evidence based practice: A conceptual framework. Qual Safety in HCare 1998 ;7(3):149158. [cited 2020 Jan 07] Available from: https://doi.org/10.1136/qshc.7.3.149.

22. Cane J, O'Connor D, Michie S. Validation of the theoretical domains framework for use in behaviour change and implementation research. Imp Sci. 2012;7(1). [cited 2020 Jan 07] Available from: https://doi.org/10.1186/174 8-5908-7-37.

23. Kirk MA, Kelley C, Yankey N, Birken SA, Abadie B, Damschroder, L. A systematic review of the use of the consolidated framework for implementation research. Imp Sci. 2016;11(1). [cited 2019 mar 09]Available from: https://doi.org/10.1186/s13012-016-0437-z DOl: https://doi.org/10.11 86/s13012-016-0437-z.

24. Damschroder $\sqcup$, Aron DC, Keith RE, Kirsh SR, Alexander JA, Lowery JC. Fostering implementation of health services research findings into practice: A consolidated framework for advancing implementation science. Imp Sci. 2009; 4(1). [cited 2019 mar 09] Available from: https://doi.org/10.1186/1748-5908-4-50.

25. Kadu MK, Stolee P. Facilitators and barriers of implementing the chronic care model in primary care: A systematic review. BMC Fam Pract. 2015;16(1). [cited 2019 Feb 05] Available from: https://doi.org/10.1186/s12875-014-02190 DOl: https://doi.org/10.1186/s12875-014-0219-0.
26. Aimola L, Jasim S, Tripathi N, Tucker S, Worrall A, Quirk A, et al. Impact of peer-led quality improvement networks on quality of inpatient mental health care: Study protocol for a cluster randomized controlled trial. BMC Psychiatry. 2016;16(1). [cited 2020 Feb 19] Available from: https://doi.org/1 0.1186/s12888-016-1040-1 DOI: https://doi.org/10.1186/s128880161040.

27. Pronovost PJ, Hudson DW. Improving healthcare quality through organisational peer-to-peer assessment: Lessons from the nuclear power industry. BMJ Qual Saf. 2012;21(10):872-75. [cited 2020 Feb 19] Available from: https:/doi.org/1 0.1136/bmjqs-2011-000470 DOl: https://doi.org/10.1136/bmjqs-2011-000470.

28. Walpola RL, McLachlan AJ, Chen TF. A scoping review of peer-led education in patient safety training. Am J Pharm Educ. 2018 ;82(2):6110. [cited 2020 Feb 19] Available from: https://doi.org/10.5688/ajpe61 10 DOl:https://doi.org/10.5688/a jpe6110, A Scoping Review of Peer-led Education in Patient Safety Training.

29. Bennett D, O'Flynn S, Kelly M. Peer assisted learning in the clinical setting: An activity systems analysis. Adv Health Sci Educ Theory Pract. 2015;20(3): 595-610. [cited 2020 Feb 20] Available from: https://doi.org/10.1007/s1045 9-014-9557-x DOI: https://doi.org/10.1007/s10459-014-9557-x.

30. Roberts D. Friendship fosters learning: The importance of friendships in clinical practice. Nurse Educ Pract. 2009;9(6):367-71. [cited 2020 Feb 21] Available from: https://doi.org/10.1016/j.nepr.2008.10.016 DOI: https://doi. org/10.1016/j.nepr.2008.10.016.

31. Clini E, Castaniere I, Tonelli R. Looking for a chronic care model in COPD patients. Eur Respir J. 2017;51(1):1702087. [cited 2019 Mar 01] Available from: https://doi.org/10.1183/13993003.02087-2017 DOl: https://doi.org/1 0.1183/13993003.02087-2017

32. Primary Care Innovation Collaborative Report. 2019. Best Care Chronic Obstructive Pulmonary Disease Program for Primary Care.

33. Best Care Chronic Obstructive Pulmonary Disease Report. 2020. Primary Care Innovation Collaborative.

34. Canadian Network for Respiratory Care. Certification for Asthma, Respiratory, COPD and Tobacco Educators. Canada: Canadian Network for Respiratory Care; n.d.. [cited 2021 Apr 30] Available from: http://cnrchome.net/certification.html

35. Health Quality Ontario. Chronic Obstructive Pulmonary Disease - Care in the Community for Adults. 2018. Availale from: https://www.hqontario.ca/ evidence-to-improve-care/quality-standards/view-all-quality-standards/ chronic-obstructive-pulmonary-disease

36. Kondro W. Family physicians urged creation of 'medical homes' for every Canadian. CMAJ. 2009 ;181(12). [cited 2021 Apr 30] Available from: https:/ www.cmaj.ca/content/181/12/885

37. Abma TA, Stake RE. Science of the particular: An Advocacy of Naturalistic Case Study in Health Research. Qual Health Res. 2014 ;24(8):1150-61. [cited 2019 Feb 15] Available from: https://doi.org/10.1177/1049732314543196 DOI: https://doi.org/10.1177/1049732314543196

38. Stake RE. The art of case study research. USA: SAGE; 1995.

39. Breimaier HE, Heckemann B, Halfens RJ, Lohrmann C. The consolidated framework for implementation research (CFIR): A useful theoretical framework for guiding and evaluating a guideline implementation process in a hospital-based nursing practice. BMC Nurs. 2015;14(1). [cited 2019 Jan 08] Available from: https://doi.org/10.1186/s12912-015-0088-4 DOl: https:// doi.org/10.1186/s12912-015-0088-4.

40. Litosseliti L. Using focus groups in research. London: A\&C Black; 2003.

41. Sibbald SL, Ziegler BR, Maskell R, Schouten K. Implementation of interprofessional team-based care: A cross-case analysis. J of Interprof Care. 2020 :1-8. [cited 2021 Apr 24] Available from: https://doi.org/10.1080/13561820.2020.1803228, 1, 8.

42. Bauer MS, Miller CJ, Kim B, Lew R, Stolzmann K, Sullivan J, et al. Effectiveness of implementing a collaborative chronic care model for clinician teams on patient outcomes and health status in mental health. JAMA Netw Open. 2019;2(3); e190230. [cited 2019 Feb 17] Available from: https://doi.org/10.1001/jama networkopen.2019.0230 DOl: https://doi.org/10.1001/jamanetworkopen.2019.0230.

43. Brown CH, Kellam SG, Kaupert S, Muthén BO, Wang W, Muthén LK, et al. Partnerships for the design, conduct, and analysis of effectiveness, and implementation research: Experiences of the prevention science and methodology group. Adm Policy Ment Health. 2012;39(4):301-16. [cited 2019 Feb 17] Available from: https://doi.org/10.1007/s10488-011-0387-3 DOI: https://doi.org/10.1007/s10488-011-0387-3.

44. Huang K, Kwon SC, Cheng S, Kamboukos D, Shelley D, Brotman LM, et al. Unpacking partnership, engagement, and collaboration research to inform implementation strategies development: Theoretical frameworks and emerging methodologies. Front Public Health. 2018;6. [cited 2019 Feb 17] Available from: https://doi.org/10.3389/fpubh.2018.00190 DOl: https://doi.org/10.3389/fpubh.2018. 00190, 6 
45. Sibbald S, Schouten K, Sedig K, Maskell R, Licskai, C. Key Characteristics and Critical Juctures for Successful Interprofessional Networks in Healthcare - A case study. 2020 [cited $2020 \mathrm{Jul}$ 17].

46. Kim CR, Free C. Recent evaluations of the peer-led approach in adolescent sexual health education: A systematic review. Perspect Sex Reprod Health. 2008 40(3):144-51. [cited 2020 Feb 19] Available from: https://doi.org/10. 1363 /4014408 DOl: https://doi.org/10.1363/ifpp.34.0089.08.

47. Weir NM, Newham R, Dunlop E, Bennie M. Factors influencing national implementation of innovations within community pharmacy: A systematic review applying the consolidated framework for implementation research. Imp Sci. 2019;14(1). [cited 2020 Apr 16] Available from: https://doi.org/10.11 86/s13012-019-0867-5 DOl:https://doi.org/10.1186/s13012-019-0867-5.

48. Hagedorn HJ, Wisdom JP, Gerould H, Pinsker E, Brown R, Dawes M, et al. Implementing alcohol use disorder pharmacotherapy in primary care settings: A qualitative analysis of provider-identified barriers and impact on implementation outcomes. Addict Sci Clin Pract. 2019;14(1). [cited 2020 Apr 12] Available from: https://doi.org/10.1186/s13722-019-0151-7 DOl: https:// doi.org/10.1186/s13722-019-0151-7.

49. Stevenson L, Ball S, Haverhals LM, Aron DC, Lowery J. Evaluation of a national telemedicine initiative in the Veterans Health Administration: Factors associated with successful implementation. J Telemed Telecare. 2018;24(3):168-78. [cited 2020 Apr 12] Available from: https://doi.org/10.11 77/1357633×16677676 DOI: https://doi.org/10.1177/1357633X16677676.

50. King ES, Moore CJ, Wilson HK, Harden SM, Davis M, Berg AC. Mixed methods evaluation of implementation and outcomes in a communitybased cancer prevention intervention. BMC Public Health. 2019;19(1). [cited 2020 Apr 11] Available from: https://doi.org/10.1186/s12889-019-7315-y DOl: https://doi.org/10.1186/s12889-019-7315-y.

51. Greenhalgh T, Robert G, MacFarlane F, Bate P, Kyriakidou O. Diffusion of innovations in service organizations: Systematic review and recommendations. Milbank Q. 2004;82(4):581-629. [cited 2020 May 28] Available from: https://doi.org/10.1111/j.0887-378x.2004.00325.x DOl: https:// doi.org/10.1111/j.0887-378X.2004.00325.x.

52. Aarons GA, Green AE, Palinkas LA, Self-Brown S, Whitaker DJ, Lutzker JR, et al. Dynamic adaptation process to implement an evidence-based child maltreatment intervention. Imp Sci. 2012 [cited 2020 Jan 15];7(1). Available from: https://doi.org/10.1186/1748-5908-7-32 DOI: 10.1186/17485908732.

53. Ault-Brutus A, Lee C, Singer S, Allen M, Alegría M. Examining implementation of a patient activation and self-management intervention within the context of an effectiveness trial. Adm Policy Ment Health. 2014 [cited 2019 Feb 14];41(6):777-87. Available from: https://doi.org/10.1007/s 1 0488-013-0527-z DOl: https://doi.org/10.1007/s104880130527z.

54. Uvhagen $\mathrm{H}$, Hasson $\mathrm{H}$, Hansson J, Von Knorring M. Leading top-down implementation processes: A qualitative study on the role of managers. BMC Health Serv Res. 2018;18(1). [cited 2020 May 01] Available from: https:// doi.org/10.1186/s12913-018-3360-y DOl: https://doi.org/10.1186/s12913-01 8-3360-y.

55. Yapa HM, Bärnighausen T. Implementation science in resource-poor countries and communities. Imp Sci. 2018;13(1). [cited 2020 May 01] Available from: https://doi.org/10.1186/s13012-018-0847-1.

56. Feifer C, Ornstein SM, Nietert PJ, Jenkins RG. System Supports for Chronic Illness Care and Their Relationship to Clinical Outcomes. Top Health Inf Manage. 2001;22(2):65-72. [cited 2020 Apr 18] Available from: https:// pubmed.ncbi.nlm.nih.gov/11761794/

57. Feifer C, Mora A, White B, Barnett BP. Challenges to improving chronic disease care and training in residencies. Acad Med. 2006;81(8):696-701. [cited 2020 Apr 18] Available from: https://doi.org/10.1097/00001888-2 00608000-00004 DOl: https://doi.org/10.1097/00001888-200608000-00004.

58. Pfadenhauer LM, Gerhardus A, Mozygemba K, Lysdahl KB, Booth A, Hofmann B, et al. Making sense of complexity in context and implementation: The context and implementation of complex interventions (CICl) framework. Imp Sci. 2017;12(1). [cited 2020 Apr 16] Available from: https://doi.org/10.1186/s13012-017-0552-5.

59. Kruger J, Dunning D. Unskilled and unaware of it: How difficulties in recognizing one's own incompetence lead to inflated self-assessments. J Personality and Psych. 1999;77(6). [cited 2020 Nov 18] Available from: https://doi.apa.org/doiLanding?doi=10.1037\%2F0022-3514.77.6.1121

\section{Publisher's Note}

Springer Nature remains neutral with regard to jurisdictional claims in published maps and institutional affiliations.

Ready to submit your research? Choose BMC and benefit from:

- fast, convenient online submission

- thorough peer review by experienced researchers in your field

- rapid publication on acceptance

- support for research data, including large and complex data types

- gold Open Access which fosters wider collaboration and increased citations

- maximum visibility for your research: over $100 \mathrm{M}$ website views per year

At BMC, research is always in progress.

Learn more biomedcentral.com/submissions 